\title{
Medische gegevens in het digitale verkeer
}

\author{
Citation for published version (APA):
}

Sanders, H. W. A. (1995). Medische gegevens in het digitale verkeer. Maastricht University. https://doi.org/10.26481/spe.19950221hs

Document status and date:

Published: 21/02/1995

DOI:

10.26481/spe.19950221hs

Document Version:

Publisher's PDF, also known as Version of record

\section{Please check the document version of this publication:}

- A submitted manuscript is the version of the article upon submission and before peer-review. There can be important differences between the submitted version and the official published version of record.

People interested in the research are advised to contact the author for the final version of the publication, or visit the DOI to the publisher's website.

- The final author version and the galley proof are versions of the publication after peer review.

- The final published version features the final layout of the paper including the volume, issue and page numbers.

Link to publication

\footnotetext{
General rights rights.

- You may freely distribute the URL identifying the publication in the public portal. please follow below link for the End User Agreement:

www.umlib.nl/taverne-license

Take down policy

If you believe that this document breaches copyright please contact us at:

repository@maastrichtuniversity.nl

providing details and we will investigate your claim.
}

Copyright and moral rights for the publications made accessible in the public portal are retained by the authors and/or other copyright owners and it is a condition of accessing publications that users recognise and abide by the legal requirements associated with these

- Users may download and print one copy of any publication from the public portal for the purpose of private study or research.

- You may not further distribute the material or use it for any profit-making activity or commercial gain

If the publication is distributed under the terms of Article $25 \mathrm{fa}$ of the Dutch Copyright Act, indicated by the "Taverne" license above, 


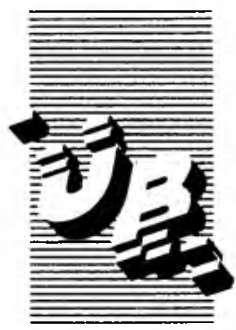

De uitleentermijn verstrijkt op:

\section{OKT. 1998 \\ 07 MEI $20 \Omega 2$}

Universiteit Maastricht

Postbus 616

6200 MD Maastricht

Gelieve deze publicatie tijdig te retourneren of (telefonisch) verlen. ging van de uitleentermijn aan te vragen.

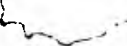

L' 
Medische gegevens in het digitale verkeer

Rede

uitgesproken ter gelegenheid van het afscheid als hoogleraar gezondheidszorgbeleid aan de Rijksuniversiteit Limburg op 21 februari 1995

door

prof. dr mr HW A Sanders 


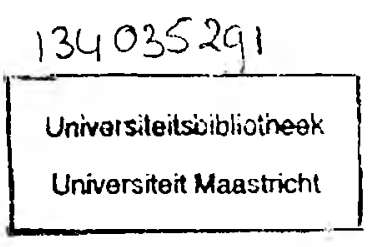


Mijnheer de Rector Magnificus,

Leden van de universitaire gemeenschap,

Geachte toehoorders.

Nu krachtige PC's per maand honderd gulden goedkoper worden, of betere waar bieden voor dezelfde prijs, en in de schappen van de supergrutter naast OMO-Power staan uitgestald, nu de NS en kabelnetexploitanten, te zamen met South Bell USA, in concurrentie treden met PTT-Telecom, nu de Nederlandse overheid meent via een door vier departementen gesteund inhaalprogramma ook op het gebied van de electronische snelwegen dé toegangspoort van Europa te kunnen worden,

nu de media de virtual reality hebben ontdekt en wekelijks schrijven over de zegeningen van Internet en over de Global Village van vice-president Al Gore, zal ook de medisch professie zijn positie moeten gaan bepalen in de informatiemaatschappij van het digitale tijdperk.

Men hoeft geen beroepsfuturoloog te zijn om te kunnen voorspellen dat binnen 5 à 10 jaren op het briefpapier van iedere arts - al dan niet via een scherm geprojecteerd - onder het telefoonnummer en eventueel het fax-nummer, een E-mail-adres wordt vermeld, dat wat betreft de zakelijke post de brievenbus steeds leger en de electronische mailbox steeds voller zal worden, en

dat de beroepsmatige communicatie - in tekst, beeld en geluid - grotendeels vanuit de werkkamer zal plaatsvinden.

Dat tot op heden in de praktijk relatief weinig gebruik is gemaakt van de mogelijkheden die de informatietechnologie biedt, is te wijten aan de nog steeds op spreken/luisteren en schrijven/lezen georiënteerde verspreiding van kennis en aan het individuele karakter van het medisch handelen, waarop het vastleggen van gegevens op een per discipline verschillende status en de berichtgeving op eigen briefpapier goed aansluiten. Ook wet- en regelgeving gaan hiervan uit. Daarbij komt, dat de gebruikersonvriendelijke presentatie van computerprogramma's en het door fanatieke insiders gebruikte jargon bij de uitleg van werkingsprincipes, de toepassing van electronica voor het opslaan en uitwisselen van medische gegevens niet hebben bevorderd.

Deze voordracht heeft vooral betrekking op de betekenis van het digitale medisch dossier en de berichtgeving langs electronische weg, voor (voornamelijk) curatief werkzame artsen. 


\section{Begrippen}

In de curatieve sector ontstaan 'medische gegevens' in de interactie tussen patiënt en hulpverlener en worden grotendeels bepaald door (a) het actuele probleem van de patiënt, (b) de kennis, kunde en ervaring van de behandelend geneesheer en de wetenschappelijke concepties van dat moment, (c) het stadium van observatie, diagnostieki en verloop, en (d) de omstandigheden. Het zijn dus geen gegevens ván de patiënt maar gegevens betréffende de patiënt, door/namens de arts verkregen in het kader van de medische beroepsuitoefening.

Het vastleggen/registreren van medische gegevens - inclusief indrukken, veronderstellingen, werkhypothesen en dergelijke van de behandelend geneesheer - primair bedoeld voor en ten nutte van de arts tijdens de actuele behandelingssituatie en -relatie, moet worden onderscheiden van:

de verslaglegging/rapportage, primair bedoeld als samenvatting van de hoofdzaken en conclusies, voor eigen gebruik in de toekomst en voor informatie en advisering aan de patiënt, aan andere artsen en eventueel aan derden.

Deze termen geven het begin- en eindpunt aan van een proces dat, op per geval en per arts verschillende wijze, aanvankelijk als werknotities in een status of op een patiëntenkaart (intern, informeel) en later op een medisch document of in een medisch dossier (extern, formeel), wordt weergegeven: noteren, ordenen en analyseren, concluderen (diagnose/therapie), follow-up en evaluatie.

In een cumulatief medisch dossier betreffende een bepaalde patiënt worden door de behandelend arts (en/of degenen die voor hem waarnemen of hem opvolgen) cq door de desbetreffende maatschap of het samenwerkingsverband, de voor de beoordeling en behandeling in heden en toekomst relevante medische gegevens en conclusies bijgehouden.

Op het niveau van een instelling/ziekenhuis kan de inhoud van de medische dossiers van alle bij de behandeling van een bepaalde patiënt betrokken disciplines worden samengebracht - bijvoorbeeld in chronologische volgorde - tot een integraal medisch dossier.

Ter wille van de overzichtelijkheid en toegankelijkheid kan op een index respectievelijk een verzamelstaat, een op datum gesorteerde lijst/staat worden bijgehouden van stukken, met per document enkele kerngegevens en vermelding van de auteur, die zich (waar) in een cumulatief medisch dossier respectievelijk een integraal medisch dossier van een bepaalde persoon bevinden.

\section{Wet- en regelgeving}

Wet persoonsregistraties (WPR, 28-12-88), gericht op de bescherming van de persoonlijke levenssfeer met betrekking tot persoonsregistraties. Voor persoonsgegevens van medische aard is ook van belang het Besluit gevoelige gegevens, 
ex art. 7 WPR (19-2-93).

Een persoonsregistratie is een samenhangende verzameling van op verschillende personen betrekking hebbende persoonsgegevens (gegevens herleidbaar tot een individuele natuurlijke persoon), die langs geautomatiseerde weg wordt gevoerd of die, met het oog op een doeltreffende raadpleging van die gegevens, systematisch is aangelegd.

Een juridische en maatschappelijke evaluatie van reikwijdte en toepassing van de WPR is bijna afgerond. Naar verwachting zal de WPR, mede om te voldoen aan de komende Europese richtlijn ter zake, worden vervangen door een Wet bescherming persoonsgegevens.

Wet op de beroepen in de individuele gezondheidszorg (WBIG, 11-11-93), ter vervanging van de tot dusverre geldende wettelijke regeling, inhoudende een het gehele gebied der geneeskunst bestrijkend verbod van beroepsuitoefening zonder hiertoe verleende bevoegdheid, door een regeling waarbij slechts het verrichten van bij de wet aangewezen categorieën van handelingen wordt voorbehouden aan daartoe overeenkomstig de wet gekwalificeerden.

In hoofdstuk $V$ betreffende de kwaliteit van de beroepsuitoefening wordt bepaald dat bij Algemene Maatregel van Bestuur voor degenen die in een bij de maatregel aangewezen register ingeschreven staan (zoals: artsen), regels kunnen worden gesteld, inhoudende o.a. voorschriften ter zake het houden van aantekening van gegevens omtrent de toestand van hun patiënten en de aan dezen gegeven behandeling en voorschriften ter zake de inrichting, het beheer en de bewaring van dossiers, betrekking hebbend op die patiënten. Dergelijke regels worden slechts gesteld voor zover ten aanzien van de betrokken personen van de noodzaak daartoe is gebleken.

Het beroepsgeheim is geregeld in art. 88: Een ieder is verplicht geheimhouding in acht te nemen ten opzichte van al datgene wat hem bij het uitoefenen van zijn beroep op het gebied van de individuele gezondheidszorg als geheim is toevertrouwd, of wat daarbij als geheim te zijner kennis is gekomen of wat daarbij te zijner kennis is gekomen en waarvan hij het vertrouwelijke karakter moest begrijpen.

Wet geneeskundige behandelingsovereenkomst (WGBO, 17-11-94, inwerkingtreding 1-4-95), gericht op verduidelijking en versterking van de rechtspositie van de patiënt, daarbij rekening houdend met de eigen verantwoordelijkheid van de hulpverlener voor zijn handelen.

Volgens art. 1653i, lid 1, richt de hulpverlener een dossier in met betrekking tot de behandeling van de patiënt. Hij houdt in het dossier aantekening van de gegevens omtrent de gezondheid van de patiënt en de te diens aanzien uitgevoerde verrichtingen en neemt andere stukken, bevattende zodanige gegevens, daarin op, voor zover een en ander voor een goede hulpverlening aan hem noodzakelijk is.

De hulpverlener draagt er conform art. 1653 I voor zorg, dat aan anderen dan de 
patiënt geen inlichtingen over hem dan wel inzage in of afschrift van de hem betreffende bescheiden worden verstrekt dan met diens toestemming. Onder deze 'anderen' zijn niet begrepen degenen die rechtstreeks zijn betrokken bij de uitvoering van de behandelingsovereenkomst en degene die optreedt als vervanger van de hulpverlener.

Ontwerp-richtlijn van de raad van de Europese Unie betreffende de bescherming van natuurlijke personen in verband met de verwerking van persoonsgegevens en betreffende het vrije verkeer van die gegevens (gewijzigd voorstel dd 20-694).

In de richtlijn wordt onder 'verwerking van persoonsgegevens' verstaan: elke bewerking of elk geheel van bewerkingen met betrekking tot persoonsgegevens, al dan niet uitgevoerd met behulp van geautomatiseerde procédés, zoals het verzamelen, vastleggen, ordenen, bewaren, uitwerken, wijzigen, opvragen, raadplegen, gebruiken, verstrekken door middel van doorzending, verspreidng of enige andere vorm van terbeschikkingstelling, samenbrengen, met elkaar in verband brengen, alsmede het afschermen, uitwissen of vernietigen van gegevens,

en onder 'bestand': elk gestructureerd geheel van persoonsgegevens die volgens bepaalde criteria toegankelijk zijn, ongeacht of dit geheel gecentraliseerd dan wel gedecentraliseerd is of verspreid op een functioneel of geografisch bepaalde wijze.

Volgens art. 3 zijn de bepalingen van deze richtlijn van toepassing op de geheel of gedeeltelijk geautomatiseerde verwerking van persoonsgegevens, alsmede op de niet-geautomatiseerde verwerking van persoonsgegevens die in bestanden zijn opgenomen of die bestemd zijn om daarin te worden opgenomen. De bepalingen zijn niet van toepassing op de verwerking van persoonsgegevens die door een natuurlijk persoon voor activiteiten uitsluitend voor privé-doeleinden wordt verricht.

Wat de verwerking van bijzondere/gevoelige categorieën van gegevens - zoals die welke de gezondheid betreffen - aangaat, stelt art. 8 dat de Lid-Staten de verwerking ervan verbieden, tenzij:

a de betrokkene uitdrukkelijk heeft toegestemd in een dergelijke verwerking,

b de verwerking noodzakelijk is ter verdediging van vitale belangen van de betrokkene of van een andere persoon, of

c de verwerking noodzakelijk is voor doeleinden van preventieve geneeskunde of medische diagnose, voor het verstrekken van zorgen of behandelingen of voor het beheer van gezondheidsdiensten, en wanneer die gegevens worden verwerkt door een gezondheidswerker die onderworpen is aan het in de nationale wetgeving vastgelegde beroepsgeheim of door een ander persoon voor wie een gelijkwaardige geheimhoudingsplicht geldt.

Uit bovenstaande weergave van de voomaamste wettelijke bepalingen kan worden geconstateerd, dat de regelgeving niet is toegesneden op het toene- 
mend belang van medische informatie voor de behandeling van individuele patiënten, en niet op de toegenomen mogelijkheden van de technologie voor een betere verwerking en een ruimere benutting van medische gegevens.

Met name voor de electronische opslag en het electronisch berichtenverkeer ligt zelfregulering op initiatief van de koepelorganisaties en het maken van afspraken tussen betrokken partijen meer voor de hand dan het bevorderen van (gedetailleerde) wetgeving ter zake, die - zo is gebleken - qua inhoud en toepassing onvoldoende effectief is en op de ontwikkelingen achterloopt.

\section{Medisch dossier}

In het begin van deze eeuw diende de registratie van (zintuiglike) waamemingen betreffende de individuele patiënt- zo deze al plaats vond - vrijwel uitsluitend als geheugensteun voor de arts.

Naarmate meer numerieke data - laboratoriumbepalingen, temperatuurmetingen ter beschikking kwamen en de röntgenologie zijn intrede deed, en deze gegevens van betekenis bleken voor diagnostiek en therapie, werd meer vastgelegd en gerapporteerd (learning from cases).

Daarnaast werd en wordt de patiëntenkaart gebruikt voor administratie en declaratie.

Naast de primaire betekenis van de registratie voor de actuele patiëntenzorg, voor de follow-up en eventueel voor de behandeling van de desbetreffende patiënt in de toekomst, werd geleidelijk het nut herkend van een systematische vastlegging van medische gegevens voor het klinisch wetenschappelijk onderzoek, voor het bewaken en bevorderen van de kwaliteit van het medisch handelen, voor het ondersteunen van besluitvorming, voor het vaststellen van beleid op micro-, meso- en macroniveau, voor research betreffende de zorgverlening als zodanig en voor het stelsel van zorg, etc.

Voor deze (secundaire) doelen van het vastleggen van bevindingen is het van belang,

1 dat zoveel mogelijk alle voor bewerking relevante medische gegevens betreffende een bepaalde persoon in één dossier worden bijeengebracht (cumulatief en integraal) cq dat via een index en verzamelstaat de afzonderlijke documenten en dossiers kunnen worden gelocaliseerd en - onder bepaalde voorwaarden - toegankelijk kunnen worden gemaakt;

2 dat de indeling van de documenten meer wordt gestructureerd (format) en de betekenis van de gehanteerde begrippen zoveel mogelijk eenduidig (codes en standaarden) is;

3 dat uit het totaal van gegevens, veelal geordend in chronologische zin en naar bron/auteur, bij voorkeur ook - ten aanzien van geselecteerde onderwerpen een probleem-georiënteerde benadering (Weed) of een op besluitvorming gerichte procesgang kan worden afgeleid.

Het is duidelijk dat de (werk-)aantekeningen op de status/patiëntenkaart niet met 
het oog op deze vereisten kunnen worden gemaakt. Hieruit kan wel (periodiek) een samenvatting in 'vrije tekst' worden gemaakt en electronisch worden opgeslagen (volgens de ASCll-standaard of de 10646-standaard van 1SO) waaruit via natural-language-processing bepaalde data kunnen worden geëxtraheerd.

Bevorderd moet worden dat op den duur vorm en inhoud van de voor verslaggeving en rapportage opgestelde documenten wél een directe bewerking op een hoger aggregatieniveau ten behoeve van bovengenoemde bijkomende doeleinden mogelijk maken, zodat met één 'multi-purpose' vastlegging in het medisch dossier kan worden volstaan.

Voor déze vastlegging en de bewerking daarna, is de computer uitermate geschikt; de informatica-technologie is hiervoor voldoende ontwikkeld. De benodigde veranderingen betreffen meer (a) de gezamenlijke wil van de artsen, (b) de te maken afspraken betreffende vorm en inhoud van de dossiers, (c) de beveiliging versus de toegankelijkheid van de opgeslagen medische gegevens en (d) de organisatie op praktijk- en instellingsniveau.

Als een digitaal opgeslagen medisch dossier kan worden gerealiseerd, wordt de beschikbaarheid van en de toegang tot medische gegevens niet meer bepaald door de localisatie ervan, maar door het bestaan en de kwaliteit van de registratíe en de benaderbaarheid langs electronische weg.

Behalve taaluitingen, al dan niet in vrije tekst op te slaan met behulp van bijv. de ASCIl-karakters van het alfabet, kunnen ook de andere twee gegevensmodaliteiten worden gedigitaliseerd:

- Zintuigtuiglijke waarnemingen (fysiologische verschijnselen, zoals het ECG of anatomische structuren, zoals röntgenopnamen) kunnen worden weergegegeven als beeldpunten.

- Gecodeerde begrippen (diagnosecode, patiëntnummer) worden geregistreerd op het niveau van het begrip zelf: een teken of code staat dan niet voor een klank maar - volgens afspraak - voor een (abstract) begrip of object.

\section{Electronic data interchange (EDI)}

Voor een zinvol gebruik van onderdelen van het medisch dossier voor bijv. research of beleid door anderen dan de samensteller, maar ook voor het begrijpen van medische gegevens van een verslag/rapport door degene voor wie het document (mede) is opgesteld, is minimaal vereist: interpreteerbaarheid en eenduidigheid van de tekst.

Daarom dienen de klinische data in een gestructureerde (indeling) en gestandaardiseerde (codes) wijze te worden geformuleerd en gepresenteerd.

Voor de electronische uitwisseling van gedigitaliseerde medische gegevens via $E$ mail, binnen een bepaald netwerk of met een modem over de telefoonlijn, heeft men wat de opstelling (format, syntax) en uniformering van de berichten betreft, op voorstel van de Nationale Raad voor de Volksgezondheid gekozen voor de 
vormgeving volgens EDIFACT. Er zijn afspraken gemaakt over - en er is software ontworpen voor - de indeling van berichtonderdelen (segmenten) als: de identificatie van de arts, de omschrijving van de patiënt, het adres, de laboratoriumuitslagen, etc. Door combinatie van oude en nieuwe segmenten worden berichtty. pen gemaakt. Deze zijn er o.a. voor: receptopdrachten, laboratoriumuitslagen, radiologie-aanvragen en -verslagen, pathologie-aanvragen en -verslagen en specialistenbrieven, en er is een berichtenset (MEDAUT release 2) voor het op electronische wijze uitwisselen van gegevens betrekking hebbend op het verblijf van een verzekerde in een ziekenhuis (melding en machtiging).

NB Voor multimedia-documenten (tekst, beeld en geluid) is door de International Organization for Standardization (IOS) een leveranciers-onafhankelijke, voor een ieder in een open systeem toegankelijke standaard ontwikkeld: Office Document Architecture (ODA).

Het ontwikkelen van standaarden (classificaties en codes) voor de inhoud (betekenis) van de berichten en de certificatie van de daarvoor benodigde software, wordt een taak voor de koepelorganisaties geacht. Voor zover deze standaarden meer dan één specifieke doelgroep ten goede komen, wordt een financiering van deze activiteiten uit de Centrale Kas bepleit, gezien het belang van een verbetering van de communicatie tussen verschillende zorgverleneers voor de gezondheidszorg in het algemeen en de patiënt in het bijzonder.

Het beheer over deze standaarden en de evaluatie van het gebruik zou in handen kunnen komen van een onafhankelijke stichting. Hiervoor werd aanvankelijk de stichting interconnectiviteit en Telematica voor de Nederlandse Gezondheidszorg (ITN) voorgesteld.

Wellicht wordt deze 'EDI-organisatie voor de gezondheidszorg' per 1-1-95 omgevormd tot het door het departement van WVC (thans WWS) gewenste onafhankelijke 'coördinatiepunt (platform) voor standaardisatie-vraagstukken op het gebied van de informatievoorziening in de zorgsector, bestuurd door de partijen in het veld'.

De overheid vindt namelijk de totstandkoming van algemeen geldende afspraken (standaarden) over de betekenis van (semantiek) en de vorm waarin (syntax) medische gegevens worden gepresenteerd en de wijze waarop deze worden uitgewisseld/getransporteerd (protocol) van groot belang voor alle betrokkenen. Zij stelt daarvoor de tot en met 1994 aan de NRV (vaste commissie classificatie en definities, WCC) toegekende middelen ter beschikking.

Verder zal het beleid gericht moeten zijn op de selectie - voor zover er iets te kiezen valt - van een landelijke/internationale postbus-netwerk-leverancier: toegankelijk voor alle zorgverleners, snel, veilig en betaalbaar.

\section{Beveiliging en privacybescherming}

De beveiliging van persoonsregistraties is conform de WPR opgedragen aan de houder (degene die de zeggenschap heeft over een persoonsregistratie) Hij 
draagt zorg voor de nodige voorzieningen van technische en organisatorische aard ter beveiliging van een persoonsregistratie tegen verlies of aantasting van de gegevens en tegen onbevoegde kennisneming, wijziging of verstrekking daarvan.

De objecten van beveiliging zijn: de gegevens zelf, de informatiesystemen (software), de hulpmiddelen (hardware) en de infrastructuur. De te nemen maatregelen ter bescherming van de informatie(-objecten) betreffen:

a de regeling van de fysieke toegang tot de hulpmiddelen en de bescherming van deze middelen tegen fysiek onheil;

b de geprogrammeerde (logische) maatregelen die door het informatiesysteem worden geboden (log-in, virus-detectie en verwijdering, back-ups); en

c de administratief-organisatorische maatregelen (wie doet wat, procedures) en de controle op de sub a en b genoemde maatregelen.

Volgens de Registratiekamer kent de beveiliging van informatie drie aspecten: 1 Beschikbaarheid (continuïteit): De informatie moet zonder belemmeringen beschikbaar zijn overeenkomstig daarover gemaakte afspraken en de wettelijke voorschriften (zoals die over bewaartermijinen).

2 Integriteit (betrouwbaarheid): De informatie moet in overeenstemming zijn met het afgebeelde deel van de realiteit en niets mag ten onrechte worden achtergehouden of zijn verdwenen.

3 Exclusiviteit (vertrouwelijkheid): Uitsluitend bevoegde personen hebben toegang tot en kunnen gebruik maken van de in de registratie opgenomen gegevens.

De mate van beveiliging (drie klassen, met name ter voorkóming van onjuist/oneigenlijk gebruik door niet-bevoegden) wordt afhankelijk gesteld van de schatting van de risico's op onzorgvuldig of onbevoegd gebruik van de persoonsgegevens en van de schade die dat zou opleveren. Persoonsregistraties van gevoelige (o.a. medische) gegevens worden ingedeeld in klasse 2.

In de ontwerprichtlijn van de EU wordt de vertrouwelijkheid en beveiliging van de verwerkingen van persoonsgegevens als volgt gewaarborgd:

- Een ieder die handelt onder het gezag van de voor de verwerking verantwoordelijke, alsmede de met de verwerking belaste persoon zelf die toegang heeft tot persoonsgegevens, mag deze slechts in opdracht van de voor de verwerking verantwoordelijke aan derden verstrekken.

- De Lid-Staten bepalen dat de voor de verwerking verantwoordelijke de technische en organisatorische maatregelen ten uitvoer dient te leggen die passend en noodzakelijk zijn voor de beveiliging tegen vernietiging, hetzij per ongeluk, hetzij onrechtmatig, tegen toevallig verlies, vervalsing, niet-toegelaten verspreiding of toegang, met name wanneer de verwerking betrekking heeft op de doorzending van gegevens in een netwerk, dan wel tegen enige andere vorm van onwettige verwerking van persoonsgegevens.

Deze maatregelen moeten, rekening houdend met de stand van de techniek en de kosten van de tenuitvoerlegging, een passend beveiligingsniveau garanderen, gelet op de risico's die de verwerking en de aard van te beschermen gegevens 
met zich meebrengen.

Ter bescherming van de privacy en ter waarborging van het beroepsgeheim dienen niet alleen locale beveiligingsmaatregelen te worden getroffen, maar moet ook het digitale verkeer te worden bewaakt. Voor het transport van informatie van niet-vertrouwelijke aard naar bepaalde personen, zijn de gebruikelijke log-in-procedures, het gebruik van passwords en het eventueel op eenvoudige wijze anonimiseren in het algemeen voldoende.

Medische persoonsgegevens en andere berichten met een persooonlijk/vertrouwelijk karakter dienen echter vóór verzending via EDI te worden versleuteld en bij voorkeur dient er gebruik te worden gemaakt van een electronische handtekening. Afhankelijk van het belang van het bericht kan tevens het systeem van bevestiging van verzending en ontvangst worden toegepast.

Onder cryptografie wordt verstaan, het ontwerpen en gebruiken van encryptie en decryptie - het vercifferen van klare tekst (het origineel) tot geheimtaal (het cryptogram) - en vice versa, door middel van algoritmen en bepaalde sleutels. Er zijn twee soorten algoritmen: symmetrische en asymmetrische.

Bij een symmetrisch cryptosysteem (zoals de data encryption standard, DES, van 1976) beschikken zowel de verzender als de ontvanger (partners die elkaar vertrouwen) over dezelfde geheime sleutel, waarmee de tekst kan worden vercijferd (geëncrypteerd) respectievelijk ontcijferd (gedecrypteerd). De betrouwbaarheid van dit systeem is uiteraard afhankelijk van het slechts tot twee personen beperkt blijven van het gebruik van de sleutel. Het plaatsen van een unieke digitale handtekening is met deze sleutels uiteraard niet mogelijk.

Bij de asymmetrische of public-key versleuteling is er sprake van een onderling verschillend maar bij elkaar horend sleutelpaar (bijv. het RSA-cryptosysteem, genoemd naar de ontwerpers Rivest, Shamir en Adleman uit 1977): een geheime en een openbare. Deze sleutels worden aangemaakt en voozien van een certificaat van echtheid door een vertrouwd instituut (Trusted Third Party); de secret-key wordt op naam van de eigenaar geregistreerd en aan hem afgegeven; de public-key wordt beschikbaar gesteld aan potentiële communicatiepartners van de eigenaar.

Indien de verzender een bericht encrypteert met de public-key van de geadresseerde kan de ontvanger, en hij alleen, het bericht ontcifferen. Zo is de vertrouwelijkheid van de uitgewisselde informatie verzekerd (maar niet de integriteit en de authenticiteit).

Versleutelt de berichtgever de tekst met zijn privé-sleutel, dan kan de ontvanger het bericht alleen decrypteren met de openbare sleutel van de veronderstelde afzender. Hij weet dan (vrijwel zeker) dat deze informatie van de bezitter van de geheime sleutel afkomstig moet zijn (het gebruik van de secret-key doet dienst als electronische handtekening). Hiermee staat de authenticiteit (de identiteit van de afzender en diens gebondenheid aan de inhoud) en de integriteit van het bericht vast.

Het nadeel van dit asymmetrisch versleutelingsalgoritme is, dat de encryptie en 
de decryptie veel computertijd vergt. Dit probleem is technisch (aan de encryptie gaat de functie 'hash total' vooraf) volledig oplosbaar.

Vergeleken met de verzending in een gesloten envelop per post, van met onuitwisbare inkt ondertekende documenten, aangetekend en met bericht van ontvangst, is met bovenstaande technieken de beveiliging van via EDI overgebrachte teksten minstens even goed zo niet beter te waarborgen.

Ook het fax-verkeer en telefoongesprekken kunnen worden geëncrypteerd. Door de 'cryptofoon' wordt spraak gedigitaliseerd, door middel van het RSA-systeem vercifferd, over de telefoonlijn verzonden en aan de kant van de ontvanger ontcijferd en omgezet in geluid.

\section{Chipcard/smartcard, zorgpas}

Een kaart met het formaat van een bankpas, met een chip, is een drager van een electronisch geheugen waarop/waarmee met behulp van bepaalde apparatuur informatie kan worden geschreven, gelezen, gewist of veranderd.

Behalve voor digitale opslag van gegevens kan een chipcard dienen als identificatie en autorisatie van de bezitter, zij kan toegang geven in ruimtelijk opzicht en ter verkrijging van electronisch opgeslagen informatie, en zij kan een betaalfunctie vervullen.

in het algemeen is een chipcard geen betrouwbare bron van informatie, de gegevens zijn vrijwel nooit volledig en zelden up to date.

In de gezondheidszorg zijn er enkele initiatieven in de richting van een zorgverzekeringspas en van een zorgpas voor bepaalde categorieën patiënten. Met betrekking tot deze laatste toepassing lijkt de privacy van de drager onvoldoende gewaarborgd en de juistheid en volledigheid van de opgeslagen gegevens niet te controleren, en de verantwoordelijken voor de opslag zijn niet te traceren.

In Frankrijk worden smartcards verstrekt aan bepaalde geregistreerde beroepsbeoefenaren op het terrein van de gezondheidszorg. Een dergelijke kaart kan dienen als middel voor de versleuteling van medische gegevens en als drager van de privé-sleutel voor het 'plaatsen' van een digitale handtekening.

\section{Aanbevelingen}

1 Breng structuur en systematiek aan in medische documenten en in medisch dossiers. Wacht wat dat betreft niet op landelijke overeenstemming over indeling, standaarden en codes.

2 Sla deze documenten en dossiers electronisch op en zorg voor een adekwate fysische, programmatische en organisatorische beveiliging.

3 Zorg voor sleutelwoorden in de tekst en/of maak gebruik van databaseprogramma's, waardoor selectie/sortering op naam, leeftijdscategorie, aard van het patiënt-artscontact, diagnose, behandeling, e.d., mogelijk wordt. 
4 Maak geaggregeerde gegevens uit deze documenten en dossiers dienstbaar aan wetenschappelijk onderzoek, planning en beleid.

5 Stel patiënten ervan in kennis dat medische gegevens onder code electronisch worden opgeslagen, verwerkt en waar nodig bewerkt, en geef hen desgevraagd een uitdraai van bepaalde documenten.

6 Draag ervoor zorg dat medische persoonsgegevens alleen toegankelijk cq beschikbaar zjin voor medewerkers van de eigen 'functionele eenheid' en voor bij de actuele zorg in heden en toekomst betrokken behandelend artsen. Voor verstrekking aan anderen is toestemming van de auteur en instemming van de desbetreffende geregistreerde noodzakelijk.

7 Voor het binnen netwerken of via de openbare telefoonlijn electronisch uitwisselen van gegevens over patiënten en van andere gegevens van vertsouwelijke aard, is een anonymisering, codering of versleuteling nodig. Zorg dat passwords en en- en decriptie-methoden privé en geheim blijven.

8 Blijf op de hoogte van de mogelijkheden en beperkingen van de informaticatechnologie en van de voor- en nadelen van electronische opslag en digitaal verkeer van medische gegevens.

Ik heb gezegd. 


\section{BRONNEN}

\section{Rapporten en adviezen}

EHAM consultancy

- Privacy-aspecten van de zorgpas. Rapport op uitnodiging van WVC opgesteld door het Centrum voor privacy-onderzoek te Amsterdam en uitgebracht door E Houtepen en A Mosshammer. Almere 1994.

Infosec-94

- Trusted health information systems: Management summary; Part 1. Requirements on electronic signature services; Part 2. Trusted third party services. Project van de Europese Commissie, programma van DG XIII. Versies dd 14-9-94.

\section{KNMG}

- Strategie en metabeheer voor de informatievoorziening in de gezondheidszorg; actiepunten KNMG 1994-1995. Juli 1994.

Nationale Raad voor de Volksgezondheid

- Advies electronische gegevensuitwisseling. Maart 1989, publ 5/'89.

- Advies electronic data interchange in de gezondheidszorg. Januarl 1990, publ 2/'90.

- Commentaar consequenties van het wetsontwerp geneeskundige behandelingsovereenkomst voor privacyreglementering. November 1990, publ 30/'90.

- Advies electronic data interchange in de gezondheidszorg, deel 2. Juni 1991, publ 15/'91.

- Advies onderzoeksbudget 1992 informatiebeleid. Juni 1991, publ 16/'91.

- Advies electronic data interchange in de gezondheidszorg, deel 3: de EDl-organisatie.

December 1991, publ 33/'91.

- Advies inzake financiering informatievoorziening zorg. Februari 1992, publ 3/'92.

- Advies privacy en gegevensverstrekking. Maart 1992, publ 9/'92.

- Advies uitwisseling van gedigitaliseerde gegevens in de gezondheidszorg. April 1992, publ $11 /$ '92.

- Advies EG-ontwerp-privacyrichtlijn COM (92) 422, final-SYN 287, van 15 october 1992. Mei 1993, publ 15/'93.

- Advies standaard EDIFACT-berichten betreffende MEDAUT release 2. Brief van de NRV aan de staatssecretaris WVC dd 15-12-93. Publ 37/'93.

- Coördinatie van standaardisatie; advies over coördinatie van standaardisatie van informatievoorziening. Mei 1994, publ 12/'94.

- Informatie op maat II; advies over de structurele informatiebehoefte van de rijksoverheid. Juli 1994, publ 19/'94.

- Advies cryptografie. Brief van de NRV aan de minster van WVC dd 8-7-94. Publ 20/'94.

Raad voor Verkeer en Waterstaat

- Waar een wil is, is een weg; op naar de informatiemaatschappij. Advies voorbereid door de Commissie van advies inzake post- en telecommunicatie (CAPT). Januari 1995.

Registratiekamer

- Beveiliging van persoonsregistraties. November 1994. 
SIG

- Voorkomen is beter dan genezen; model voor een toekomstige informatiebevelliging bij SIG Zorginformatie. Vertrouwelijk rapport van J A C de Jong. Utrecht, september 1994.

\section{Literatuur}

- Branger PJ et al. Electronic communication between providers of primary and secondary care. BMJ 1992; 305:1068.

- Dossier cryptologle. Computerrecht 1994/4: 138 (Smits JM), 144 (Patijn A). 150 (Dumortier J), 157 (Hoven van Genderen R van der). - Electronische snelwegen; van metafoor naar actie. Actieprogramma Electronische Snelwegen van de ministers van EZ en V\&W en de staatssecretarissen van BiZa en OCW. Op 21-12-94 verzonden naar de Tweede Kamer.

- Esch RE van. EDI en het Nederlandse recht: een inventarisatie van problemen. Computerrecht 1993/6:237.

- H Franken. Redactionele kanttekeningen: Ondoordacht. RM Themis 1994-1:1.

- Frisse ME et al. Models for patient records. Acad Med 1994; 69:546.

- Gore A. Infrastructure for the global village; a high-capacity network will not be built without government investment. Scientific American, september 1991.

- Graaf $\mathrm{F}$ de, Berkel, CJM van. Juridische aspecten van electronica in het medisch berichtenverkeer; door U of over U ? Medisch Contact 1994; 49:871.

- Lei $\mathrm{J}$ van der. The introduction of computer-based patient records in the Netherlands. Ann Intern Med 1993; 119:1036.

- McDonald CJ, Tierney WM. Computerstored medical records; their future role in medical practice. JAMA 1988; 259:3433.

- Moorman PW et al. A model for structured data entry based on explicit decriptional knowledge. Meth Inform Med 1994; 33:454.

- Rector Al et al. Foundation for an electronic medical report. Meth Inform Med 1991; 30:179.

- Reiser SJ. The clinical record in medicine. Part 2: reforming content and purpose. Ann Intern Med 1991; 114:980.

- Romunde KJ van. Elektronische communicatie in de gezondheidzorg; waar maken wij ons druk om ? Medisch Contact 1994; 49:869.

- Schuringa GJ, Kuus AHJ. Encryptie in het dataverkeer; toekomst of verleden tijd ? Computerrecht 1994/2:42.

- Shortliffe EH et al. Patient records and computers. Ann Intern Med 1991; 115:979.

- Wiemans FPE et al. Encryptie: justitiële en particuliere belangen. Delikt en Delinkwent 1994; 24:343.

- Wyatt JC. Clinical data systems, part 1: data and medical records; part 2: components and techniques; part 3: development and evaluation. Lancet 1994; 344: 1543, 1609 en 